Most production technologies require a uniform flow path of liquid from pressure distribution pipelines. To achieve this goal, it is proposed to introduce polymer additives into the liquid flow or to use converging distribution pipelines with a continuous longitudinal slot in the wall. To reduce the uneven operation of the distribution pipeline during discrete liquid dispensing, it is proposed to use cylindrical output rotary nozzles with a lateral orthogonal entry of the jet into the nozzle. The problem is the lack of methods for accurate hydraulic calculation of the operation of distribution pipelines. Adequate calculation methods are based on differential equations.

Finding the exact solution of the differential equation of fluid motion with variable path flow rate for perforated distribution pipelines is urgent, because it still does not exist. The available calculation methods take into account only the right angles of separation of the jets from the flow in the distribution pipeline. These methods are based on the assumption that the coefficient of hydraulic friction and the coefficient of resistance of the outlets are constant along the flow. A calculation method is proposed that takes into account the change in the values of these resistance coefficients along the distribution pipeline. The kinematic and physical characteristics of the flow outside the distribution pipeline are also taken into account. The accuracy of calculating the value of the flow rate of water distributed from the distribution pipeline has been experimentally verified. The error in calculating the water consumption by the method assuming that the values of the resistance coefficients are unchanged along the distribution pipeline reaches $18.75 \%$. According to the proposed calculation method, this error does not exceed $6.25 \%$. However, both methods are suitable for the design of pressure distribution pipelines, provided that the jet separation angles are straight.

Taking into account the change from $90^{\circ}$ to $360^{\circ}$ of the angle of separation of the jets from the flow in the distribution pipeline will expand the scope and accuracy of calculation methods

Keywords: pressure distribution pipeline, pressure flow of liquid with variable travel flow
UDC 532.542:532.559.3

DOI: $10.15587 / 1729-4061.2021 .246852$

\title{
THE PROBLEM OF HYDRAULIC CALCULATION OF PRESSURE DISTRIBUTION PIPELINES
}

\author{
Volodymyr Cherniuk
} Corresponding author Doctor of Technical Sciences, Professor* Department of Environmental Engineering Institute of Environmental Engineering The John Paul II Catholic University of Lublin Racławickie ave., 14, Lublin, Poland, 20-950

E-mail: v.cherniuk@ukr.net

Roman Hnativ

Doctor of Technical Sciences, Associate Professor*

O leks a nd r Kravchuk

$\mathrm{PhD}$, Associate Professor

Department of Water Supply and Drainage

Kyiv National University of Construction and Architecture Povitroflotskyi ave., 31, Kyiv, Ukraine, 03037

Vad y m Orel

$\mathrm{PhD}$, Associate Professor*

Iryna Bihun

Postgraduate Student

Department of Heat and Gas Supply and Ventilation**

Matvi Cherniuk

Department of Electronic Devices

Institute of Telecommunications, Radioelectronics and Electronic Engineering**

*Department of Hydraulic and Water Engineering** ** Lviv Polytechnic National University Stepana Bandery str., 12, Lviv, Ukraine, 79013

Received date 27.09.2021

Accepted date 07.12.2021

Published date 21.12.2021
How to Cite: Cherniuk, V., Hnativ, R., Kravchuk, O., Orel, V., Bihun, I., Cherniuk, M. (2021). The problem of hydraulic calculation of pressure distribution pipelines. Eastern-European Journal of Enterprise Technologies, 6 (7 (114)), 93-103. doi: https://doi.org/10.15587/1729-4061.2021.246852
1. Introduction

Pressure distribution pipelines (DP) is common in many processes. In irrigation, they form the basis of sprinkler, drip (Fig. 1) and subsurface irrigation systems. DP is used for aeration of water in water treatment facilities in order to remove iron hydroxide, free carbon dioxide and hydrogen sulfide from water. DPs are part of aerators in biological wastewater treatment plants (aeration tanks (Fig. 2), air filters, biofilters) to ensure the vital activity of microorganisms (aerobic bacteria), mineralizing organic matter and other contaminants dissolved in wastewater. Pressure DPs are important components in fire-fighting water supply, in particular, in sprinkler (automatic) and deluge (semi-automatic) fire extinguishing systems. Pressure DP are the main functional elements of spray pools and cooling towers when cooling circulating water in nuclear and thermal power plants (NPP and TPP) $[1,2]$.

Turbines of TPPs and NPPs are also equipped with distribution pressure pipelines with directing nozzles that direct the jet of working steam to the blades of the turbine wheel [1]. Supply ventilation of the premises is a network of pressurized DP. In agricultural aviation, when spraying plants, pressure distribution pipelines are fixed under the wings of a propeller-driven aircraft [1]. Pressure DPs are widely represented in the technological processes of the chemical, petrochemical and oil industries, as well as in other production processes and technologies.

In practice, the uneven operation of pressure distribution pipelines is realized [3]. In a long DP, the highest working head $H$ is formed at its beginning. Therefore, the maxi- 
mum flow rate of the liquid $Q$ is at the first outlet nozzle: $Q=\mu \omega \sqrt{2 g H}$. Further, along the DP, the head of the liquid $H$ drops and reaches the smallest value at the last nozzle. In most technological processes, a prerequisite is to ensure the uniformity of liquid distribution along the DP. Ensuring this condition requires the creation of a perfect computational apparatus and an important task of hydromechanics. The widespread use of pressure DP in various branches of technology indicates the relevance of the theoretical and practical solution to this problem.

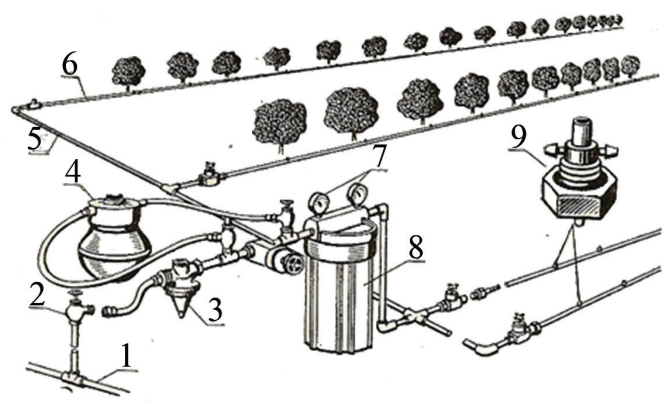

Fig. 1. Diagram of the garden drip irrigation system: 1 - main pipeline; 2 - latch; 3 - pressure regulator; 4 - container with fertilizers; 5 - first order distribution pipeline (DP-1);

6 - the same, second order (DP-2, irrigation pipeline); 7 - manometers; 8 - filter; 9 - droppers (water nozzles)

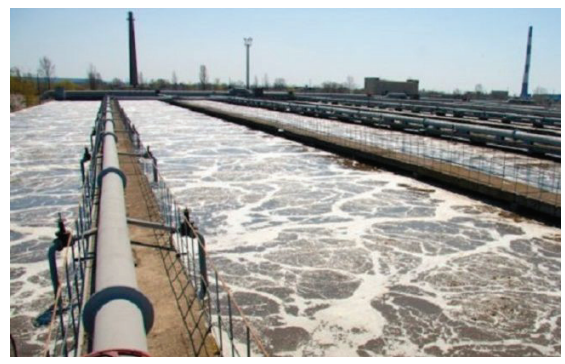

a

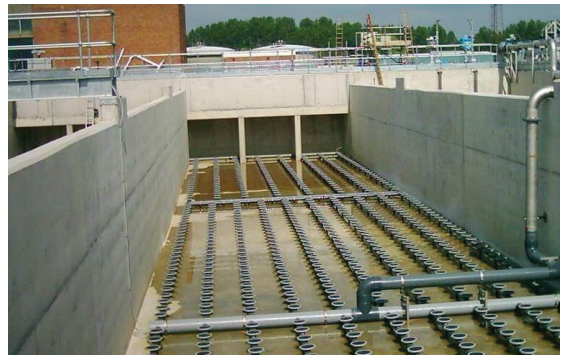

b

Fig. 2. Aeration tank: $a-$ in the process of work; $b-$ aeration tank pressure distribution air duct system

Back in the seventies of the twentieth century. Attempts have been made to calculate DP using analytical equations. It is recommended to calculate the piezometric head in the DP section containing $\mathrm{n}$ outlets, according to the formula in which the average velocity of the main flow is $V=V_{\text {init }}$, and the hydraulic friction coefficient $\lambda=\lambda_{\text {init }}$, that is, they are the same as at the beginning of DP. However, this does not reflect reality. Since $V \neq$ const in DP, unequal modes of fluid movement and different laws of hydraulic resistance can exist along the flow, that is, $\lambda \neq$ const.

However, an accurate hydraulic calculation of pressure distribution pipelines can only be achieved by applying the theory of variable flow hydraulics based on differential equations. This theory is based in Russia at the turn of the $19^{\text {th }}$ and $20^{\text {th }}$ centuries. The differential equation of motion for a fluid with a variable flow rate (DEMFVR) for perforated distribution pipelines was obtained in 1937 in Kharkiv. For a non-cylindrical perforated distribution pipeline DEMFVR looks like this [3]:

$$
\begin{aligned}
& d\left(\frac{\alpha_{\mathrm{o}} V^{2}}{2 g}\right)+\frac{d p}{\rho g}+d z+i_{f} d x+ \\
& +\frac{\alpha_{\mathrm{o}}(v \cos \beta-V) \cdot V}{g} \frac{d Q}{Q}=0,
\end{aligned}
$$

where $\alpha_{o}$ - the coefficient of momentum of the flow, $\alpha_{o}=1.03 \ldots 1.05 ; V$ - the average velocity of the main flow inside the perforated pipeline; $v$ - the velocity of the jet, disconnected from the main stream; $p$ - the fluid pressure inside the DP; $d z=\sin \psi d x$ - geometric difference in the axis of the pipeline in its section of length $d x ; \psi$ - the angle of inclination of the pipeline axis to the horizon; $i_{f} d x=d h_{x}$-friction head loss along the length of the pipeline; $\beta$ - the angle between the vectors of the velocities $V$ and $v ; Q$ - the flow rate of the main fluid flow inside the DP.

For a cylindrical distribution pipeline DEMFVR (1) is simplified, since its cross-sectional area is $\Omega=$ const, and $d Q=\Omega \cdot d V$, where $Q=\Omega \cdot V[1]$ :

$$
\frac{\alpha_{\mathrm{o}}(v \cos \beta-2 V) \cdot d V}{g}+\frac{d p}{\rho g}+\sin \psi \cdot d x+d h_{x}=0 .
$$

Equations (1) and (2) do not have an exact solution to date.

\section{Literature review and problem statement}

The authors of [4], who applied a number of simplifying assumptions and introduced the momentum exchange coefficient, made up a differential equation (3) for the impulse of forces acting on a local branch of the jet at an angle $\beta=90^{\circ}$ from the main flow flowing in the pressure distribution pipeline [4]:

$$
\begin{aligned}
& \frac{1}{\rho} \frac{d p}{d x}+\frac{\lambda}{2 D} V_{0}^{2}(1-x / L)^{2 z}+ \\
& +V_{0}^{2}[\alpha+2 z \xi \ln (1-x / L)] \frac{d(1-x / L)^{2 z}}{d x}=g I,
\end{aligned}
$$

where $p$ - the hydrodynamic pressure;

$\rho$ - the density of the liquid;

$\lambda$ - the hydraulic coefficient of friction;

$D$ - DP diameter;

$V_{0}$ - the flow rate at the entrance to the DP;

$L$ - the length of the perforated part of the DP;

$x$ - the current coordinate of the length of the DP;

$\alpha$ - the coefficient of change in the force impulse for the first outlet;

$\xi$ - (in the original $\beta$ ) modified coefficient of change in the impulse of the force of jet detachment from the main stream flowing in the DP, $\xi=\Delta V^{2} / V^{2} ; g$ - acceleration of gravity; $I$ - longitudinal slope of the DP;

$z$ - the exponent, three variants of its value are considered $(z<1$, when the force of the jet detachment momentum is greater than the friction force, and the velocity gradually increases along the flow, $z=1$, when the friction force is equal to 
the jet detachment momentum force, and the velocity varies linearly along the stream, $z>1$, in this case the friction force is greater than the impulse force, and the velocity gradually decreases along the flow).

Equation (3) does not fully reflect the work of a pressure head DP, since it is based on a number of simplifications. Applying a number of additional assumptions, the authors of [4] made an analysis of the probability of equation (3). However, no solution to equation (3) was provided. The reason for this is the laboriousness and lengthy process of solving the differential equation.

However, a number of approaches to the integration of DEMFVR (1) and (2) have been proposed [3]. The authors of [5], disregarding the loss of pressure for separating the mass in a long DP, and taking $\beta=90^{\circ}$ and $\lambda=$ const, compiled the DEMFVR for a pressure DP. However, the hydraulic coefficient of friction cannot be constant along the length of the DP, since the flow rate of the liquid along the flow decreases. According to the message of the author of work [6], the calculation according to the equation given in [5], at $\lambda=$ const, gives a deviation from the experimental data by $38 \%$. However, provided that $\lambda \neq$ const, the deviation decreased to $20 \%$ [6].

In [7], when solving equations (1) and (2), a linear law of change in the flow rates of disconnected jets was adopted, which also does not correspond to the actual picture of the phenomenon under consideration. In addition, the authors of [7] neglected the change in the position of the axis of the main flow (the angle $\psi(x)$ of its inclination to the horizon), the loss of energy of the flow for friction in the sections between the branches of the jets. However, a nonlinear law of variation of the main flow rate in the DP was adopted. However, according to the formula obtained with the listed assumptions, it is possible to calculate only a separate branch of the jet from the DP [7].

The method for calculating pressure distribution pipelines, given in [8], is based on the approach proposed by the author [9] when solving DEMFVR for pressure collecting pipelines, that is, for flows with a track mass connection. When solving the DEMFVR in work [8], the values of the following quantities were taken constant along the length of the DP:

a) DP diameter ( $D=$ const);

b) the distance between the outlet holes;

c) coefficient of liquid flow through the outlet ( $\mu=$ const);

d) hydraulic coefficient of friction $(\lambda=$ const);

e) the angle of branching of the jets $\left(\beta=\right.$ const $\left.=90^{\circ}\right)$;

f) the angle of inclination of the DP axis to the horizon $\left(\psi=\right.$ const $\left.=0^{\circ}\right)$.

As a result of mathematical transformations, the differential equation (4) with one unknown variable $\bar{Q}$ was obtained in dimensionless form [8]:

$$
-\frac{d \bar{Q}}{d \bar{y}} \cdot \frac{d^{2} \bar{Q}}{d \bar{y}^{2}}-(2-m) \bar{Q} \frac{d \bar{Q}}{d \bar{y}}+\frac{\varsigma_{l}}{2 f} \bar{Q}^{2}=0,
$$

where $\bar{Q}=Q / Q_{\text {beg }}$;

$Q$ - the main flow rate in the section x DP;

$Q_{b e g}$ - the same, at the beginning of the DP;

$\underline{h}=\sqrt{2 g h} / V_{b e g}-$ piezometric fluid head in the DP;

$\bar{f}=\mu a l / \Omega$;

$a=\Sigma \omega_{\mathrm{o}} / l$

$m=v \cos \beta / V$ - the coefficient of the detachable mass;

$v$ is the velocity of the jet outflow from the hole in the wall of the DP;
$V$ - the velocity of the main flow in the DP;

$\beta$ - the angle between the directions of movement of the detachable jet and the main flow;

$\bar{y}=1-\bar{x}-$ the relative distance measured upstream from the end of the DP;

$\bar{x}=x / l-$ the same, following the flow from the beginning of the DP.

According to [8], for relatively short DPs, the piezometric line constantly grows along the main flow (Fig. 3 , curve $a$ ). In distribution pipelines of intermediate length, it first decreases, has an inflection point curve $\left(x_{i n f}\right)$, and then increases (Fig. 3, curve $b$ ). For long DPs, the piezometric line decreases along the flow and reaches its lowest position at the end of DP (Fig. 3, curve $c$ ).

For DP with different relative lengths (short, intermediate, long), different solutions of eq. (4) are obtained under the condition of a turbulent regime of fluid motion. For example, for a long DP, the roots of equation (4) are as follows [8]:

$$
\bar{Q}=\frac{\operatorname{sh}(k \bar{y})}{\operatorname{sh} k} ; \bar{h}=\frac{k \cdot \operatorname{ch}(k \bar{y})}{\bar{f} \cdot \operatorname{sh} k},
$$

where the coefficient $k$ is found from expression (6):

$$
k^{3}-B k+\operatorname{ctg}(k \bar{y})=0,
$$

or according to the graph shown in Fig. 4 [8].

Equations (4)-(6) [8] give good results for calculating $\mathrm{DP}$, provided that the diameter of the DP and the distance between the outlet holes are constant along the length of the DP, its longitudinal axis is horizontal $\left(\psi=0^{\circ}\right)$, the jets are disconnected from the DP at right angles $\left(\beta=90^{\circ}\right)$, and the hydraulic coefficient of friction $\lambda(x)$ and the coefficient $\mu(x)$ of the fluid flow rate through the outlet nozzles are constant along the DP. However, there are no DPs with such characteristics in nature.

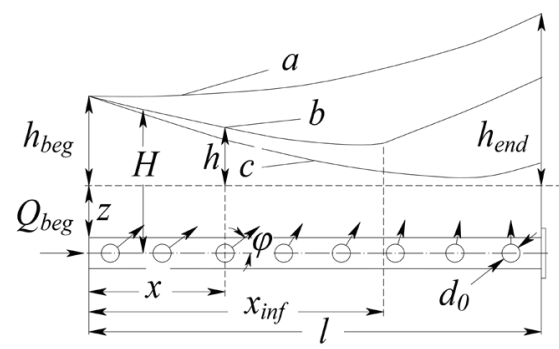

Fig. 3. Scheme of operation and the type of piezometric lines for pressure head DP: $a$ - relatively short; $b$-intermediate; $c$ - relatively long [8]

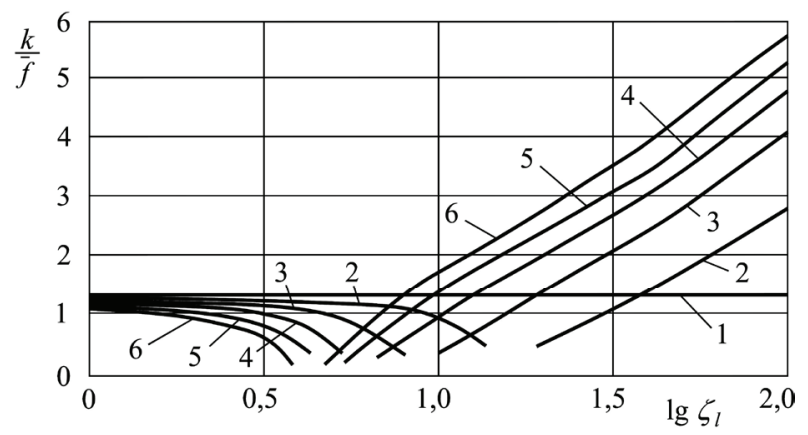

Fig. 4. Graph for determining the coefficient $k$ to formulas (5) at different values of: $1-(1) ; 0.8-(2) ; 0.6-(3) ; 0.4-(4)$; $0.2-(5) ; 0-(6)[8]$ 
In the literature, many results of an experimental study of the operation of DP have been published. It has been found that a decrease in the uneven distribution of liquid along the pressure head DP is achieved by introducing polymer applications into the flow [10]. The latter reduce turbulent friction in cylindrical pipelines and change the hydraulic resistance of pipes of variable diameter [11].

With the help of numerical and physical experiments $[12,13]$, a decrease in the unevenness of the track distribution of liquid with DP equipped with:

a) rectangular outlet openings;

b) the same, round;

c) a longitudinal continuous rectangular slit.

At the beginning of the DP, a branching of the jets from the flow in the DP at an angle $\beta$ equal to $68^{\circ}$ was formed. Along the DP, with a decrease in the flow energy, the angle $\beta$ increased and at the end of the DP was $90^{\circ}$ [12]. Numerous experiments have found that the slightest irregularity of the path distribution of liquid with DP is provided by a continuous slot [13].

The uneven distribution of water along the conical DP is less than that along the cylindrical DP [14]. The smallest unevenness is achieved when the inlet diameter $D_{\text {beg }}$ of the tapered DP is twice the final diameter $D_{\text {end }}$. The subsequent increase in the ratio of diameters $D_{\text {beg }} / D_{\text {end }}$ caused an increase in the unevenness of the track distribution of water [14]. On the basis of an analytical analysis of literature sources, the authors of [15] came to the conclusion that the slightest uneven distribution of liquid from a pressure head DP can be achieved in a confuser DP with a continuous slot in its wall.

A decrease in the uneven distribution of liquid along the DP is also achieved by reducing the distance between the outlets and increasing their area along the flow. The kinematic characteristics of the outlet jets are influenced by the shape of the outlet holes arranged in the wall of a rectangular DP and the thickness of the DP wall [16]. With an increase in the wall thickness of the DP from 2 to $10 \mathrm{~mm}$, the coefficient of narrowing of the flow $\varepsilon$ at the outlet from the hole increased, and the uneven distribution of water along the flow decreased. The uneven operation of the DP was weakened with a decrease in its duty cycle (duty cycle). Less irregularity of the track distribution of water is observed when it flows through the holes arranged in the DP with thicker walls. The results obtained in [16] suggest that this tendency will increase with the outflow of water through the packing.

Investigation [17] of water leakage through holes arranged in the wall of the irrigation pipeline, it was found that the value of the flow coefficient $\mu$ depended on the angle $\beta$. The angle $\beta$, in turn, was a function of the flow rate and pressure in the pipeline, in the alignment of the outlets [17].

An effective method [18] is to regulate the unevenness of the track distribution of liquid with DP using cylindrical rotary nozzles with a lateral orthogonal entry of the jet into the nozzle. By returning the nozzles with respect to their longitudinal axes, the value of the angle $\beta$ changes in the range from 0 to $360^{\circ}$ and, accordingly, the unevenness of the DP operation is significantly regulated [18].

The influence of the geometric parameters and the shape of the branching of the jets from the flow in the DP on the uneven distribution of the working fluid with the DP in the heat exchanger with parallel flows were experimentally investigated [19]. For a two-phase medium (liquid together with gas), the slightest irregularity of the DP operation was obtained when ascending flows entered vertical pipes [20]. Reducing the uneven distribution of methanol from DP into the catalyst microchannels during steam reforming can be a key factor for increasing the productivity of hydrogen production [21].

The work [22] presents the results of studies of DP, mounted in chemical devices, in work [23] - in solar collectors, in article [24] - in nuclear reactors. The results of experimental studies serve as the basis for constructing mathematical models of fluid flows, in particular, differential equations.

In theoretical and experimental studies [4-24], the issues of creating a method for calculating DP at indirect angles of jet separation $\left(\beta \neq 90^{\circ}\right)$ and taking into account the variable along the flow value of the hydraulic friction coefficient $(\lambda(x) \neq$ const) and the coefficient of fluid flow through outlet nozzles $\left(\mu_{(x)} \neq\right.$ const). The reason for this is the difficulty of taking into account all the characteristics of the flows in the pressure head DP when solving the DEMFVR. This problem, in addition to taking into account the value of the angle $\beta \neq 90^{\circ}$, was eliminated in [25].

Based on the design scheme (Fig. 5) of the pressure flow with jet separation, the author of [25] supplemented the differential equation of fluid motion with variable flow rate (2) with the term $p_{\text {out }}(d Q / v)$. This term takes into account the force $S$, which replaces the action of the part of the detachable jet thrown back in section 3-3. Thus, let's obtain equation (7) [25]:

$$
\begin{aligned}
& \frac{\alpha_{0}(v \cos \beta-2 V) d V}{g}+d \frac{p}{\rho g}+ \\
& +\frac{p_{\text {out }}}{\rho g} \frac{d V}{v} \cos \theta+\sin \psi \cdot d x+d h_{x}=0 .
\end{aligned}
$$

The variables $V, d V, v, d p, p_{\text {out }}, d h_{x}, d x$ in equation (7) [25] are expressed not because of the flow rate $Q_{x}$, as in the works analyzed above [5,7-9], but because of the total head $H_{(x)}$ at the distribution pipe, under the influence of which the jets leak, and through an independent variable distance $x$. The angles $\beta, \theta, \psi$ and $\xi$ (Fig. $5-7$ ) vary from $0^{\circ}$ to $360^{\circ}$, and $m_{(x)}=\left(v_{(x)} \cos \beta\right) / V_{(x)} \neq$ const, where $\xi$ is the angle between the velocity vectors $\overline{v_{(x)}}$ of the detachable jet (in the outlet section of the outlet-hole) and $\overrightarrow{V_{\text {out }}}$ of the external flow (Fig. 6).

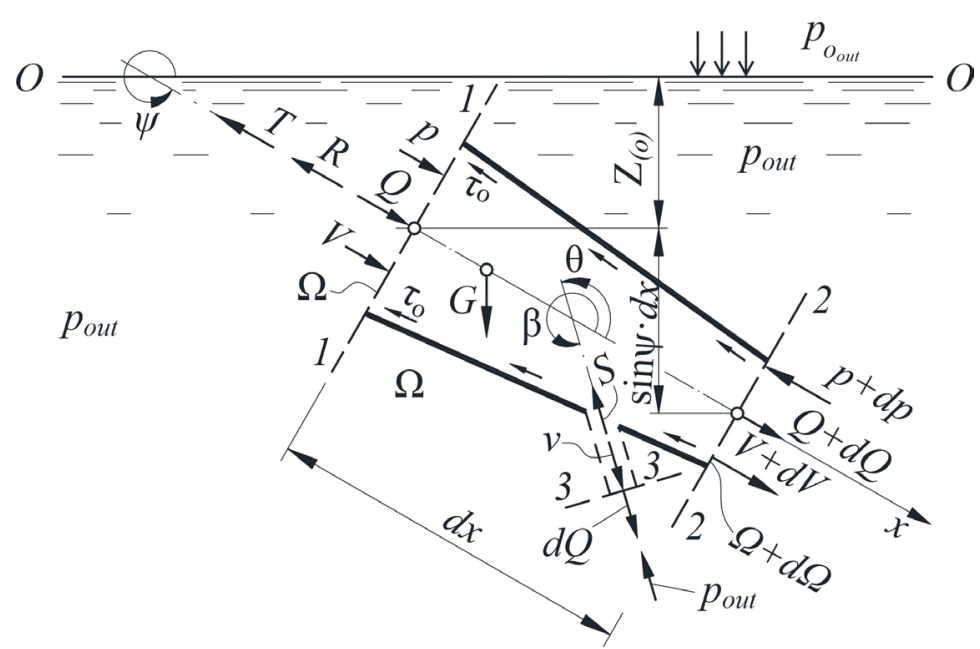

Fig. 5. Design diagram of a pressure flow with jet separation [1] 


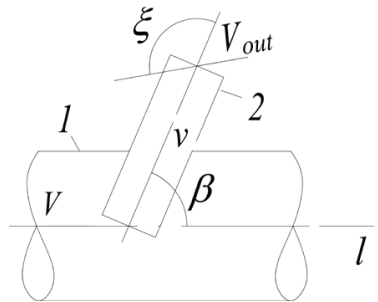

Fig. 6. Angles between the directions of the velocities of the main flow $V$ in the distribution pipeline, the detachable jet $v$ and the external flow $V_{\text {out }} ; 1$ - DP; 2 - outlet nozzle [1]

As a result of solving the supplemented DEMFVR (7), the author [25] obtained dependence (8) for calculating the flow rate in pressure distribution pipelines laid in an external fluid flow. Since it is advisable to calculate the DP with a stroke from the end to the head, the $x$-axis is directed against the flow in DP, which is reflected in equation (8) and in Fig. 7.

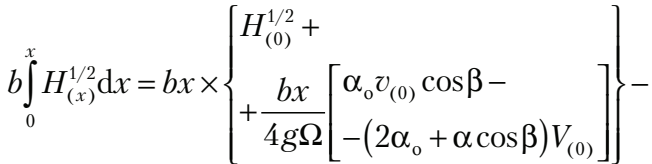

$$
\begin{aligned}
& -\frac{b x}{4 H_{(0)}^{1 / 2}}\left\{\begin{array}{l}
\lambda_{(x)} \frac{x}{D} \frac{V_{(0)}^{2}}{2 g}+\left(2-\frac{\rho_{\text {out }}}{\rho}\right) x \sin \psi+ \\
+f_{(x)}\left[\frac{p_{o_{\text {out }}}}{\rho g}+\frac{\rho_{\text {out }}}{\rho}\left(T_{(0)}+\frac{\alpha V_{\text {out }}^{2}}{2 g} \cos \xi\right)\right] \cos \beta
\end{array}\right\} .
\end{aligned}
$$

The total liquid head in the pressure distribution pipeline (Fig. 7) is calculated according to the dependence (9). Formula (9) was obtained by differentiating equation (8) [25]:

$$
\begin{aligned}
& H_{\left(x_{k}\right)}=
\end{aligned}
$$

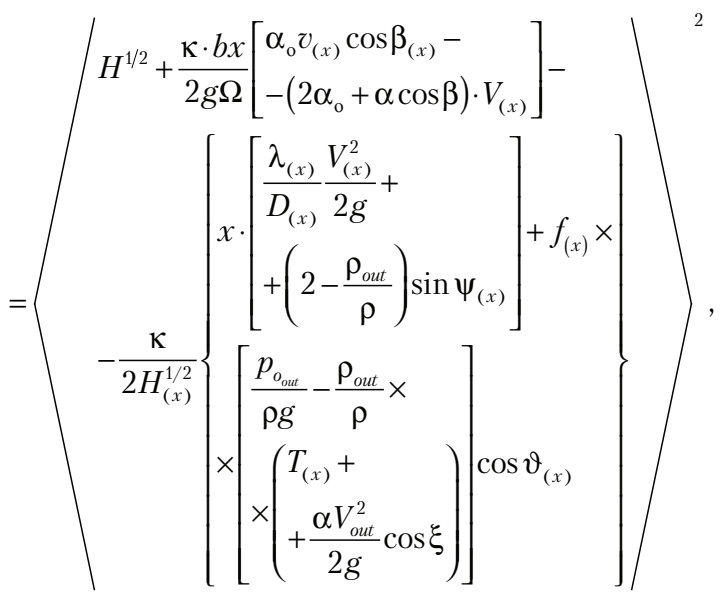

where in equations (8), (9) [25]:

$$
b \int_{0}^{x} H_{(x)}^{1 / 2} \mathrm{~d} x-\text { an increase in the liquid flow rate in the }
$$
upstream direction on the calculated section of length $x_{i-k}$ inside the distribution pipeline, numerically equal to the distribution of liquid from the DP in the same section $x_{i-k}$;

$H_{\left(x_{k}\right)}$ - required full working head in the design section $k$ (Fig. 7);

$H_{\left(x_{i}\right)}$ - output (known from calculations in the previous section) working head in the design section $i$;

$T_{(0)}$-immersion depth of the DP axis at the beginning of the calculated section at $x=0$ (Fig. 7 ); $\beta_{\left(x_{i}\right)}$ - the angle between the vectors of the average velocity $\vec{V}$ of the main fluid flow in the DP and the cutoff jet $\vec{v}$, (Fig. 5-7);

$\vartheta_{\left(x_{i}\right)}$ - the angle between the vectors of the average velocity $\vec{V}$ of the main fluid flow in the DP and the force $\vec{S}$, replacing the action of the rejected part of the detachable jet $\theta=\beta+180^{\circ}$ (Fig. 5);

$\xi_{\left(x_{i}\right)}$ - the angle between the vectors of velocities $\overrightarrow{v_{(x)}}$ of the detachable jet and the external flow $\overrightarrow{V_{\text {out }}}$ (Fig. 6);

$D_{\left(x_{i}\right)}$ - the angle between the horizontal $0-0$ and the $l$-axis of the flow (Fig. 7);

$D_{\left(x_{i}\right)}-$ inner DP diameter;

$b_{i-k}$ - coefficient constant in the calculated section $i-k$, $b_{i-k}=n_{i-k} \mu_{i} \omega_{\text {hole }_{i-k}} \sqrt{2 g}=$ const, $\mathrm{m}^{1.5} / \mathrm{s}$;

$n_{i-k}$ - the number of outlets per unit of length DP, $\mathrm{m}^{-1}$;

$\mu_{i}$ - coefficient of discharge of the outlet-hole;

$\omega_{\text {hole }_{i-h}}$ - area of one outlet-hole;

$x_{i}-$ the index at the symbols of the parameters of the equations indicates their belonging to the beginning of the calculated section $i-k$, that is, to the $i$-th cross-section of the DP;

$\kappa$ - empirical coefficient, $\kappa \approx 0.6-0.9$;

$V_{\left(x_{i}\right)}=Q_{\left(x_{i}\right)} / \omega_{\left(x_{i}\right)}-$ the average water flow rate inside the DP;

$\omega_{\left(x_{i}\right)}$ - cross-sectional area of DP;

$v_{\left(x_{i}\right)}=\phi \sqrt{2 g H}=a H_{\left(x_{i}\right)}^{1 / 2}-$ the velocity of the jet outflow through the outlet in the $i$-th section of the DP, $a=\phi \sqrt{2 g}$;

the multiplier $\cos \phi_{\left(x_{i}\right)}$ in the expression

$$
\left(2 \alpha_{0}+\alpha \cos \phi_{\left(x_{i}\right)}\right) \cdot V_{\left(x_{i}\right)},
$$

of those participating in the first square brackets, which takes into account the effect of the dynamic head of the flow flowing inside the DP on the surface of the free section of the detachable jet;

$\rho, \rho_{\text {out }}$ - respectively, the density of the liquid inside the DP and outside it;

$f_{i-k}=(b x / a \omega)_{i-k}=\left(n x \varepsilon \omega_{h o l e} / \omega\right)_{i-k}-$ pore volume (perforation) of DP in the calculated section $i-k$;

$\varepsilon_{i-k}-$ coefficient of compression of the jet in the outlet (nozzle);

$p_{o_{\text {out }}}$ - fluid (or air) pressure outside the DP;

$\lambda_{\left(x_{i}\right)}^{o_{\text {out }}}$ - hydraulic coefficient of friction (Darcy coefficient); $\lambda_{(x)}$ is calculated using known formulas depending on the flow regime and the values of the Reynolds criterion $\operatorname{Re}_{\left(x_{i}\right)}$. On the calculated sections $x_{i-k}$ located between two adjacent outlets (or nozzles), the water flow rate in the DP is unchanged, therefore the value of the Darcy coefficient in these sections of the flow is assumed to be constant $\lambda_{i-k}=$ const. In the calculations, it is taken into account that the laminar flow regime is realized when $\operatorname{Re}_{\left(x_{i}\right)} \leq 2320$. The zone of the turbulent regime of fluid movement includes three sections of hydraulic resistance, respectively: a section of hydraulically smooth pipes at $\operatorname{Re}_{\left(x_{i}\right)}\left(\Delta_{\left(x_{i}\right)} / D_{\left(x_{i}\right)}\right)<10$, a section of pre-square resistance of hydraulically rough pipes at $10 \leq \operatorname{Re}_{\left(x_{i}\right)}\left(\Delta_{\left(x_{i}\right)} / D_{\left(x_{i}\right)}\right) \leq 500$ and a section of quadratic resistance of hydraulic pipes at $\operatorname{Re}_{\left(x_{i}\right)}\left(\Delta_{\left(x_{i}\right)} / D_{\left(x_{i}\right)}\right)>500$.

The value of the Reynolds criterion for the flow in the distribution pipeline:

$$
\operatorname{Re}_{\left(x_{i}\right)}=\frac{Q_{\left(x_{i}\right)} D_{\left(x_{i}\right)}}{\Omega_{\left(x_{i}\right)} v_{\left(x_{i}\right)}},
$$

where $v_{\left(x_{i}\right)}-$ the kinematic viscosity. 


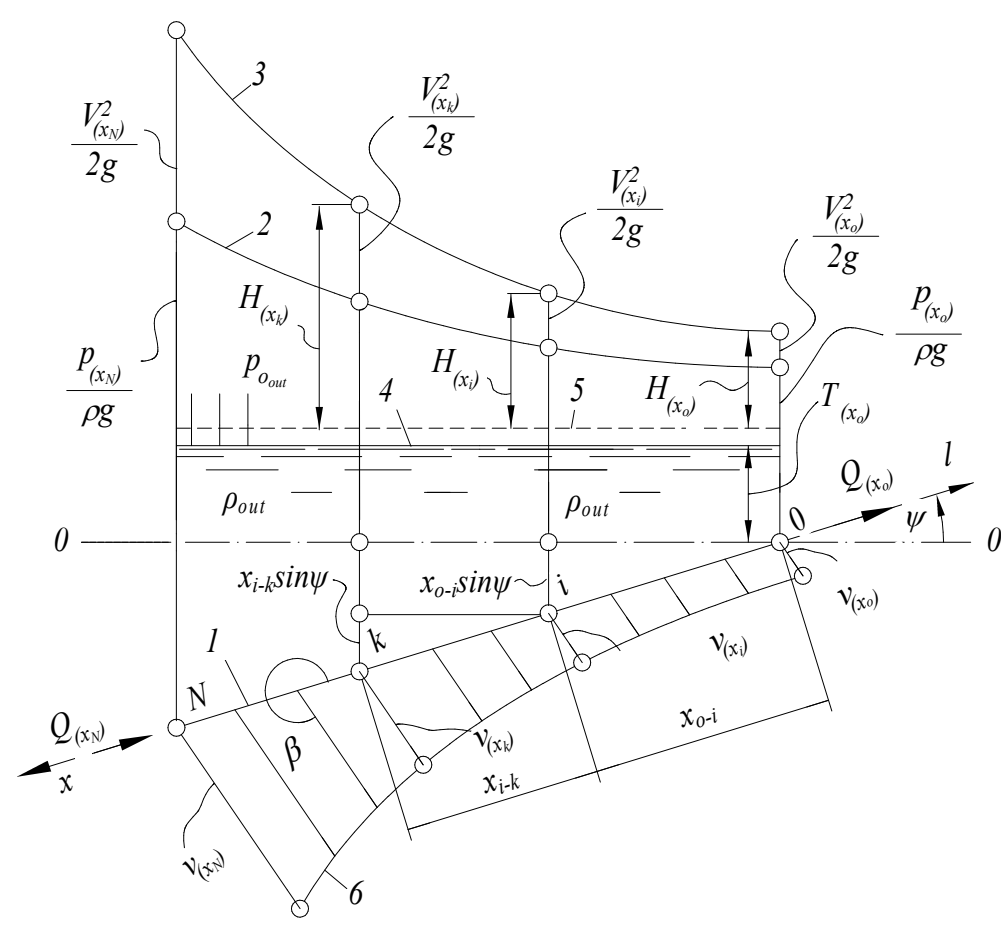

Fig. 7. Design diagram of the distribution pipeline (DP): $1-D P$;

2 - piezometric line for the flow in the DP; 3 - the same, full pressure line;

4 - flow surface outside the DP; 5 - line of total pressure for external flow DP; 6 - diagram of detachable jet velocities; / - axis of the DP (the $x$ axis is directed to the counter flow in the DP) [25] particular, laid in an external fluid flow with different kinematic and physical characteristics.

To achieve the aim, the following objectives were set:

- to carry out experiments at the stand with gravitational water supply to the distribution pipeline;

- to compare the calculation results of pressure distribution pipelines with experimental data.

\section{Materials and methods of research}

The initial materials for the study were the results of integration of the differential equation of fluid motion of variable flow rate (1), represented by formulas (5) and (6) [8], and dependences (8)(11) [25] for the hydraulic calculation of DP.

The accuracy of calculating the distribution of water along the pressure head DP, obtained by formulas (5) and (6) [8], as well as the reliability of its own equation (8) for calculating flow $Q_{\left(x_{k}\right)}$ and dependence (9) [25] for calculating the values of the total liquid head $H_{\left(x_{k}\right)}$ in the distribution pipeline was verified by experiments on experimental DP.

\section{Experimental verification of methods of hydraulic calculation of pressure head DP}

The discharge coefficient of the outlet holes (nozzles) $\mu_{\left(x_{i}\right)}$, as well as the Darcy coefficient $\lambda(x)$, is variable along the DP. For a cylindrical outlet nozzle at $F r_{\left(x_{i}\right)}>10$, $W e_{\left(x_{i}\right)}>200$ and full compression and sharp leading edges, the value $\mu_{\left(x_{i}\right)}$ can be calculated using empirical formulas obtained from the data [26]. For example, for the ratio $l / d=1 \ldots 1,5, \operatorname{Re}_{t h_{\left(x_{i}\right)}}=10^{3} \ldots 10^{5}$, or $l / d=2 \ldots 5, \operatorname{Re}_{t h_{\left(x_{i}\right)}}=50 \ldots 15 \cdot 10^{4}$, or $l / d=10 \ldots 50, \operatorname{Re}_{t h_{\left(x_{i}\right)}}=80 \ldots 15 \cdot 10^{4}, \operatorname{Re}_{t h_{\left(x_{i}\right)}}=80 \ldots 15 \cdot 10^{4}$, the values $\mu_{\left(x_{i}\right)}$ are found by the formula (11) [26]:

$$
\mu_{\left(x_{i}\right)}=\frac{1}{1.23+\frac{58 \cdot l}{\operatorname{Re}_{t h\left(x_{i}\right)} d}},
$$

$l, d$ - the length and diameter of the outlet nozzle; $\operatorname{Re}_{t h_{(x)}}=\sqrt{2 g H_{\left(x_{i}\right)}} \cdot d / v-$ Reynolds criterion for a jet in a nozzle at a theoretical velocity of water flow through it.

The work [25] presents the result of solving the augmented DEMFVR (7) taking into account the variable along the DP values of the hydraulic friction coefficient $\left(\lambda_{(x)} \neq\right.$ const $)$ and the coefficient of fluid flow through the outlet nozzles $\left(\mu_{(x)} \neq\right.$ const). However, the problem arose of experimental verification of the obtained solution and its comparison with the results of the integration of DEMFVR (1) [3] by other scientists.

\section{The aim and objectives of research}

The aim of research is to experimentally verify the known methods of hydraulic calculation of pressure distribution pipelines and to improve these mathematical models. This will provide a reliable calculation and controlled adjustment of uneven distribution of liquid along pressure distribution pipelines, in

\section{1. Experimental stand}

An experimental stand with gravitational water supply to the distribution pipeline was used (Fig. 8) [27]. The head at the entrance to the DP was equal to $3740 \mathrm{~mm}$. The inner diameter of the investigated DP is $D=8.21 \mathrm{~mm}$, and its length is $2644 \mathrm{~mm}$ (Fig. 9). The experimental DP is equipped with eleven outlet nozzles with inner diameters $d=3.2 \mathrm{~mm}$ and lengths equal to $25 \mathrm{~mm}$ (Fig. 10). The distances between the nozzles were not the same along the DP, but multiples of 20D. The experimental distribution pipeline had a duty cycle of 1.67. The outlet nozzles and fittings for connecting the impulse lines from the piezometers were welded to the experimental DP at an angle $\beta=90^{\circ}$ (Fig. 10). DP material stainless steel [1]. DP with a horizontal axis $\left(\psi=0^{\circ}\right)$ and DP with angles $\psi$ of inclination of their axes to the horizon equal to $5.3^{\circ}$ and $354.7^{\circ}$ (Fig. 11) were investigated.

The pore volume of the distribution pipeline was calculated by the formula

$$
f=n \omega / \Omega,
$$

where $\omega$ - the cross-sectional area of the outlet nozzle, $\omega=\pi d^{2} / 4=3.14 \cdot 0.0032^{2} / 4=8.0425 \cdot 10^{-6} 6 \mathrm{~m}^{2} ; d$ - its inner diameter, $d=3.2 \mathrm{~mm}$ (Fig. 9); $n$ - the number of nozzles on the DP, $n=11 ; \Omega$ - the cross-sectional area of the experimental DP, $\Omega=\pi D^{2} / 4=3.14 \cdot 0.00821^{2} / 4=52.939 \cdot 10^{-6} \mathrm{~m}^{2} ; D$ - its diameter, $D=8.21 \mathrm{~mm}$. DP with $f=11 \cdot 8.0425 \cdot 10^{-6} / 52.939 \cdot 10^{-6}=1.67$ and DP with $f=8 \cdot 8.0425 \cdot 10^{-6} / 52.939 \cdot 10^{-6}=1.22$ were investigated. To obtain DP with lower values of the duty cycle $f$, some of the outlet nozzles on the DP were muffled.

The applied experimental DP is similar in size to DP, which are used in the overwhelming majority in practice in the technological processes of various industries. 


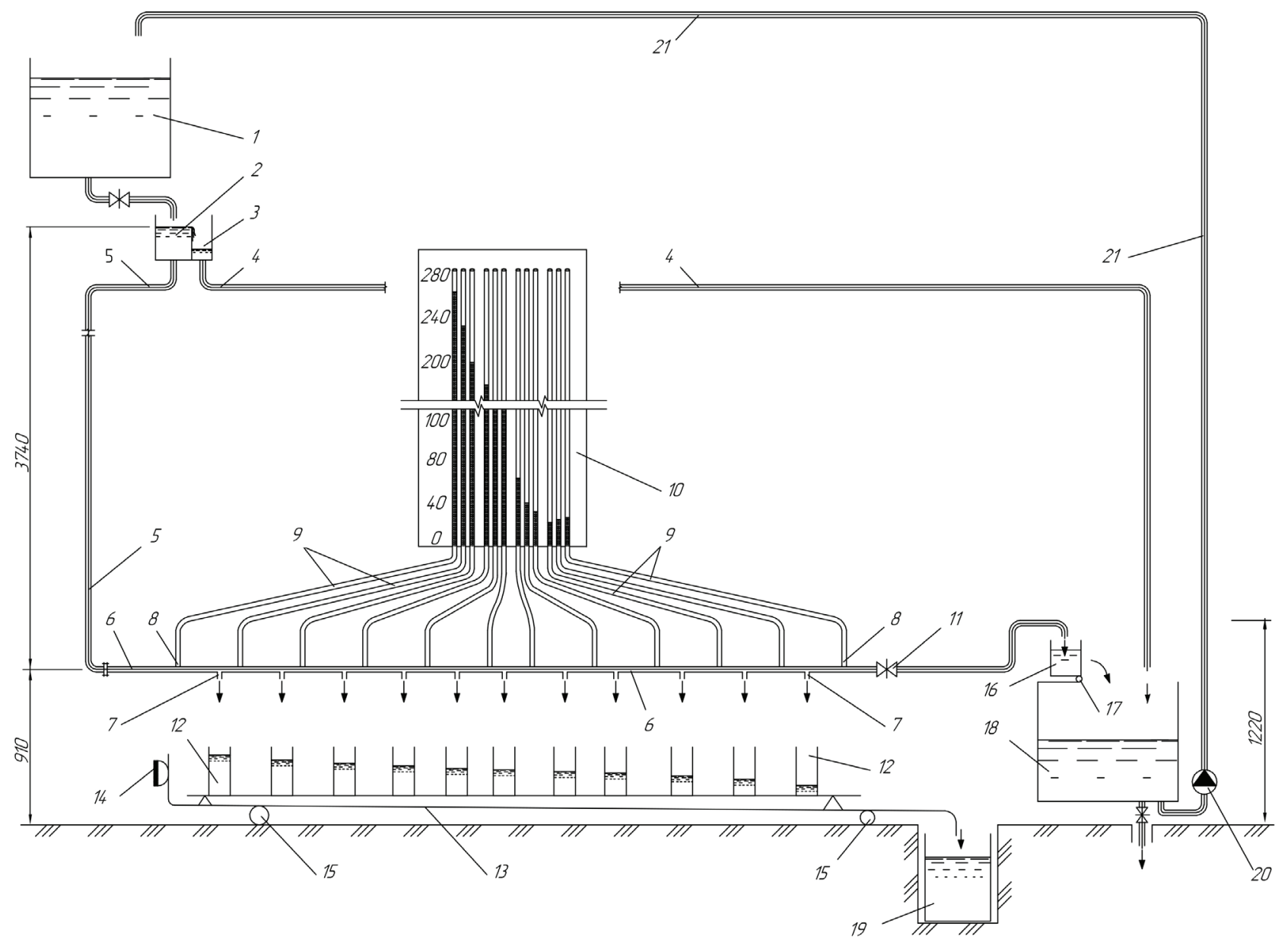

Fig. 8. Scheme of the experimental stand: 1 - water tank; 2 - pressure tank; 3 - waste tank; 4 - discharge pipeline; 5 - the same, supply; 6 - experimental distribution pipeline; 7 - outlet nozzles; 8 - fittings for connecting impulse tubes from piezometers; 9 - impulse tubes; 10 - shield with piezometers; 11 - valve; 12 - measuring vessels; 13 - movable tray; 14 - handle; 15 - rolling bearings; 16 - measuring tank; 17 - hinge; 18 - receiving tank; 19 - drainage tank; 20 - pump; 21 - pressure pipeline (dimensions are in $\mathrm{mm}$ ) [27]

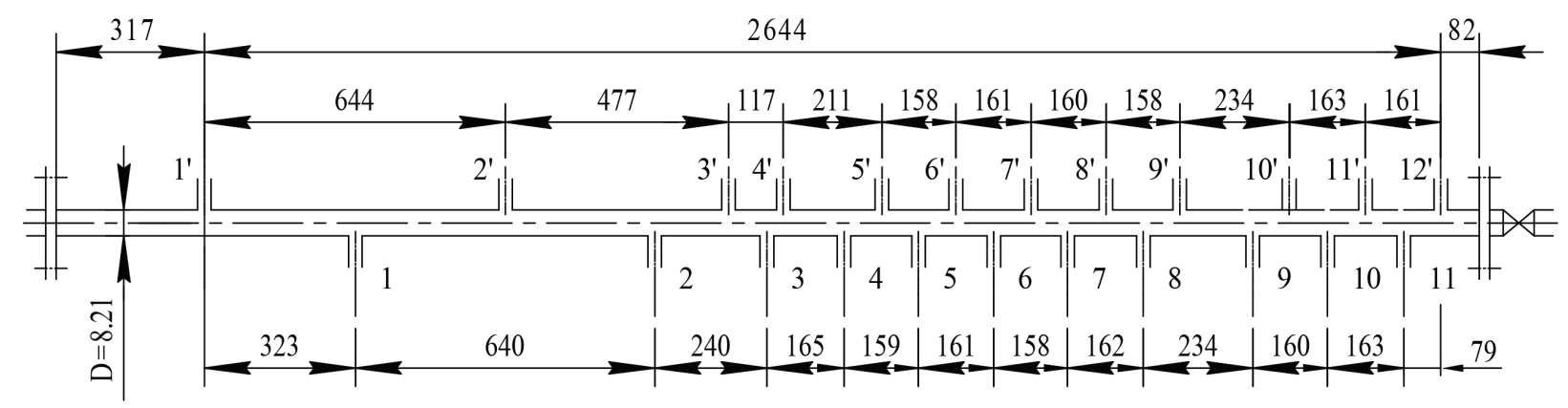

Fig. 9. Diagram of the experimental DP: 1-11- water outlet nozzles; 1 '-12 '- fittings for connecting impulse pipes from piezometers (to simplify reading the diagram, fittings 1'-12' are conventionally shown above DP; dimensions are in $\mathrm{mm}$ )

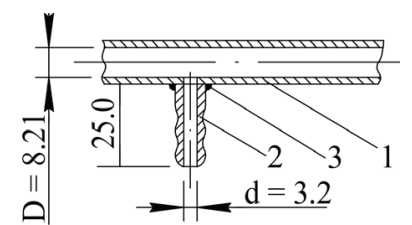

Fig. 10. DP fragment: 1 - DP wall; 2 - outlet nozzle, or fitting for connecting impulse tubes from piezometers; 3 - welded connection
The maximum average water velocity at the entrance to the experimental distribution pipeline with $f=1.67$ was $V_{\text {beg }}=Q_{\text {beg }} / \Omega=0.16 \cdot 10^{-3} / 52.939 \cdot 10^{-6}=3.022 \mathrm{~m} / \mathrm{s}$, where $\Omega=0.16 \cdot 10^{-3} \mathrm{~m}^{3} / \mathrm{s}$ (Fig. 12, b). It met the value of the Reynolds criterion $\operatorname{Re}=V D / v=3.022 \cdot 8,21 \cdot 10^{-3} / 1.01 \cdot 10^{-6}=24568$, where $v=1.01 \cdot 10^{-6} \mathrm{~m}^{2} / \mathrm{s}$ is the kinematic viscosity of water at a temperature of $20{ }^{\circ} \mathrm{C}$.

The purpose of this experimental study is to check the correctness of the solutions of the DEMFVR. The theoretical calculations made by the methods [8] and [25] were 
compared with the experimental results. The experimental DP was made in a geometric scale of 1:1 with respect to the distribution pipelines of drip irrigation systems for orchards (Fig. 1) and berry fields and at a scale of 1:3-1: 4 in relation to DP used in agricultural aviation.

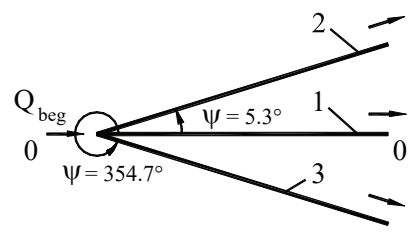

Fig. 11. The angle $\psi$ reference scheme is the inclination of the DP axis to the horizon

Hydraulic resistance in pressure pipeline flows is mainly created by frictional forces. The similarity of the action of friction forces in pressure pipeline flows of liquids is achieved while ensuring the conditions of geometric, kinematic and dynamic similarity, if for each pair at the corresponding points of nature and model the Reynolds criterion will have the same values.

For comparison, let's take DPs used in agricultural aviation when spraying plants, for example, with pesticides. With their mass concentration in water $10^{-3}-10^{-4}$, the viscosity of the pesticide solution is practically the same as the viscosity of the solvent, that is, water. The value of the Reynolds criterion is calculated for the alignment at the beginning of the DP before the first outlet nozzle. The distribution pipe of an aircraft sprayer with an outer diameter of $40 \mathrm{~mm}$ and a wall thickness of $5.5 \mathrm{~mm}$ has an inner diameter of $29 \mathrm{~mm}$. With an average velocity of an aqueous solution of a pesticide at the entrance to the DP equal to $0.90 \mathrm{~m} / \mathrm{s}$, the Reynolds criterion for the flow section in front of the first outlet nozzle $\operatorname{Re}_{\text {nature }}=v d / v=$ $=0.90 \cdot 29 \cdot 10^{-3} / 1.01 \cdot 10^{-6}=25842$. The value of the Reynolds criterion for the model (experimental DP) is calculated above. It is equal to $\operatorname{Re}_{\text {model }}=V D / v=3.022 \cdot 8,21 \cdot 10^{-3} / 1.01 \cdot 10^{-6}=24568$. The values of the Reynolds criterion calculated for nature and model differ by [(25842-24568)/25842] $100 \%=4.93 \%$, which is an acceptable deviation.

\section{2. Comparison of calculation results with experi-} mental data

The values of the water flow rate in the horizontal distribution pipeline at $\psi=0^{\circ}$ and PT with $\psi=5.3^{\circ}$ and $\psi=354.7^{\circ}$ (Fig. 11), calculated from dependencies (8)-(11) [25] practically coincide with the data of the physical experiment (Fig. 12).

The results of calculating the piezometric heads and water flow rate in the DP, obtained by formulas (8)-(11) [25] at $\psi=0^{\circ}$ and $\beta=90^{\circ}$, are also compared with the results of calculations by formulas (5) and (6) [8] as well as with experimental data (Fig. 13). In order to start calculating the DP according to the method [8], it is necessary to set the value of the flow rate of the liquid at the beginning of the DP. Since its value is unknown, and its calculation is laborious, then $Q=160.2 \cdot 10^{-6} \mathrm{~m}^{3} / \mathrm{s}$, obtained experimentally on an experimental DP with $D=8.21 \mathrm{~mm}$ (Fig. 8-10). According to the method [8], only the piezometric head is calculated at the outlet nozzles (without taking into account the velocity head) and provided that the DP is horizontal $\left(\psi_{(x)}=0^{\circ}\right)$, and the jet separation angles are straight $\left(\beta_{(x)}=90^{\circ}\right)$. In addition, by the method of [8], the hydraulic coefficient of friction $\lambda_{(x)}$ and the coefficient of the detachable mass $m_{(x)}=\left(v_{(x)} \cos \beta_{(x)}\right) / V$ are taken to be constant along the length of the DP.

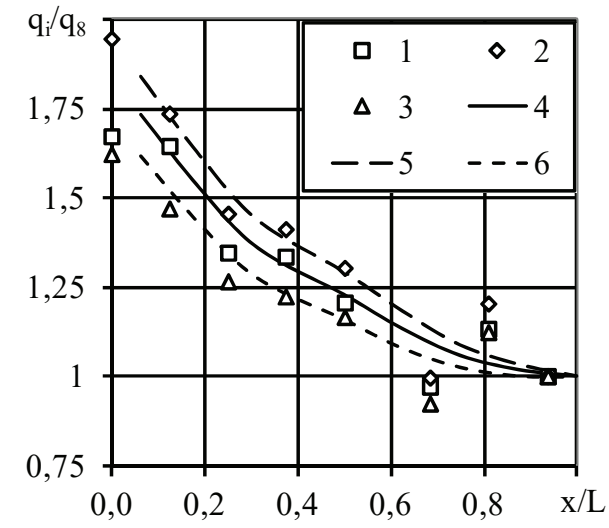

Fig. 12. Relative change in the track distribution of water along the DP with a duty ratio $f=1.22: 1-3-$ experimental data; 4-6 - calculated curves calculated by formulas (8)-(11) [25]; $11,4-\psi=0^{\circ} ; 2,5-\psi=5.3^{\circ} ; 3,6-\psi=354.7^{\circ} ; L-$ the length of the perforated part of the DP; the $\mathrm{x}$-axis is directed along the flow $\left(\beta=90^{\circ} ; Q t r=0\right)$
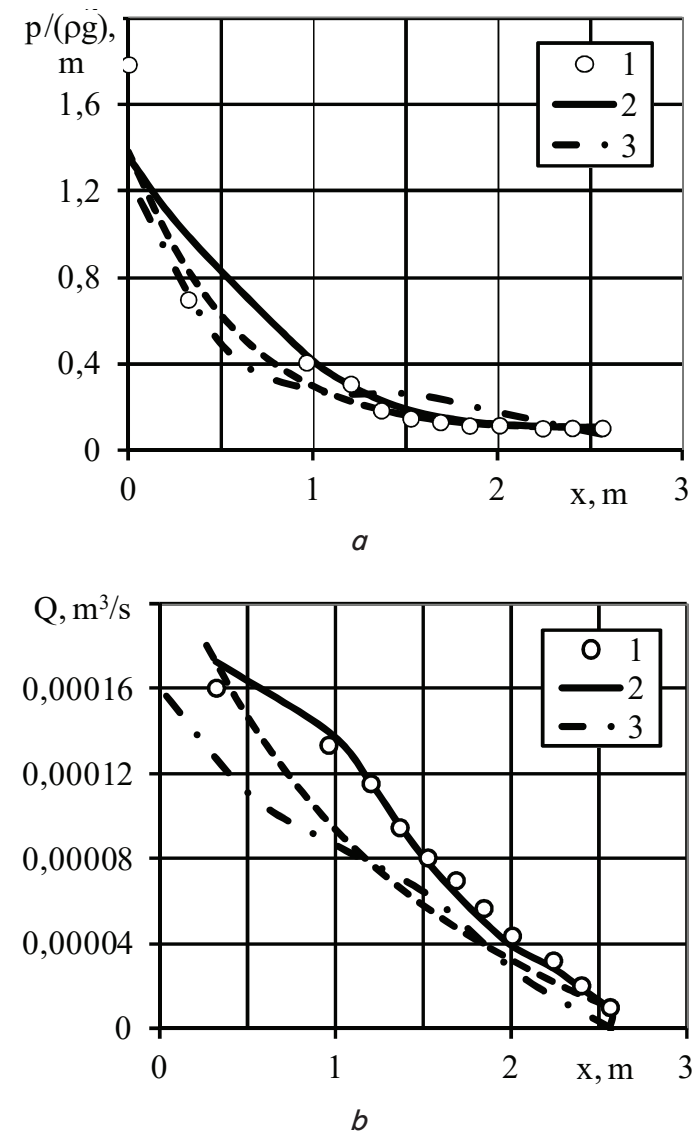

Fig. 13. Comparison of the calculation results: $a$ - piezometric pressure inside the DP; $b$ - the same, water consumption; 1 - experimental data (head at the last nozzle $\left.H_{(0)}=0.104 \mathrm{~m}, Q_{t r}=0\right) ; 2-$ curves obtained according to formulas (8)-(11) [25] at $\kappa=0.6$ and the distance between the outlet nozzles as in the experimental DP (Fig. 9); 3 - the same, according to the formulas (5) [8] with a uniform arrangement of the outlet nozzles; $4-$ curves obtained by formulas (8)-(11) [25] at $\kappa=0.6$ under the condition of uniform arrangement of the outlet nozzles $\left(\psi=0^{\circ} ; \beta=90^{\circ}\right.$; the $x$ axis is directed along the water flow in the DP; calculation curves 2 and 4 are made going counterflow from the end of the DP) 
According to the method [8], according to Fig. 4, the DP is divided into five parts equal in length, and the parameters $\bar{Q}$ and $\bar{h}$ are calculated for the sections at the border of these sections. When calculating according to the method [8], the hydraulic friction coefficient $\lambda=0.03=$ const was taken for the entire length of the DP, as for the section of hydraulically rough pipes in the zone of turbulent motion.

In order to correctly compare the method [8] with the method [25], curves 4 (Fig. 13) were additionally calculated using formulas (8)-(11), for the case when the initial nozzles are located with a constant step, since this can be calculated by the method [eight].

The method [25] takes into account the change along the DP of the values of the hydraulic friction coefficient $\lambda_{(x)}$ and the flow rate coefficient of the nozzles $\mu_{(x)}$. In order to start the calculation by the method [25], it is necessary to set the head value $H_{(o)}$ at the last outlet nozzle located at the end of the DP, which is not difficult. The experimental value $H_{(o)}=0.104 \mathrm{~m}$ was taken. The $\lambda_{(x)}$ coefficient was calculated using the formulas known from hydraulics, and the packing flow rate $\mu_{(x)}$ was calculated using the formula (11).

The flow rate of water in the DP at its beginning in the section of packing 1 (Fig. 9), calculated according to [25] (curve 2 in Fig. 13, $b$ ), is equal to $0.00017 \mathrm{~m}^{3} / \mathrm{s}$. The water flow rate obtained according to [8] (curve 3 ) is equal to $0.00013 \mathrm{~m}^{3} / \mathrm{s}$. The experimental value (array of points 1) of the water flow rate at the nozzle 1 is $0.00016 \mathrm{~m}^{3} / \mathrm{s}$. Consequently, the water flow rate at the beginning of the DP, calculated according to [25], is $6.25 \%$ higher than the experimental value of a, the flow rate obtained according to [8] is $18.75 \%$ less than the experimental value. Thus, the hydraulic calculations of the water flow rate for the remaining length of the DP (nozzles 2-11) according to formulas (8), (9) [25] for pressure DP with jet diversion angles $\beta=90^{\circ}$ practically coincide with the experimental data and differ by $25,0-39.7 \%$ of the calculation results according to the method [8]. It should be recalled that the methodology [8] does not provide the calculation of DP with an uneven arrangement of the outlet nozzles.

\section{Discussion of the results of the analysis of methods for calculating pressure distribution pipelines}

The data obtained as a result of physical and numerous experimental studies of fluid flows in pressure head DP are the basis for constructing mathematical models of these fluid flows.

Differential equations of motion for a fluid with variable flow rate (DEMFVR) (1) and (2) [3] have not received a rigorous mathematical solution from 1937, that is, from the time of their derivation. The reason for the long search for a solution to the DEMFVR is the objective complexity of the problem. Nevertheless, teams of authors of works [27-30] are working to eliminate this problem.

Equation (3) [4], compiled in 2017, is based on the assumption that the hydraulic coefficient of friction $\lambda_{(x)}$ is constant along the distribution pipeline and includes a number of other simplifications. Consequently, it cannot correctly reflect the real hydrodynamic processes in the pressure head DP. In addition, equation (3) requires a solution for possible practical application.
The method [5] of the hydraulic calculation of the pressure distribution pipeline is also based on the differential equation (2) [3]. However, the authors of [5] laid down in the solution the condition that $\lambda_{(x)}=$ const along the DP. Provided that $\lambda_{(x)}=$ const, the method [5], according to the author [6], gives the deviation of the calculated values from the experimental data by $38 \%$. However, equations suitable for practical calculations of pressure head DP at $\beta=90^{\circ}$ were obtained in $[8,25]$.

Methodology for calculating pressure head DP [8], originally created for the design of DP with a longitudinal horizontal axis $\left(\psi=0^{\circ}\right)$ and right angles of jet diversion $\left(\beta=90^{\circ}\right)$. Also in work [8], it is assumed that the hydraulic coefficient of friction $\lambda_{(x)}$ and the coefficient $\left.\mu_{(x)}\right)$ of the liquid flow rate through the outlet nozzles are constant along the DP. In addition, equations (1) and (2) [3], as well as expressions (4)-(6) [8] obtained on their basis, were drawn up under the condition that the liquid flows from the DP into a stationary atmosphere. Therefore, these equations do not take into account the hydrodynamic pressure of the external fluid flow.

However, in practice, DPs are used, laid in an external flow of liquid or gas. For example, with a dispersed discharge of treated wastewater into the water intake, the jets that poured out of the DP holes are warmer than the water of a river or sea. Then they float to the surface of the reservoir. In summer, on the contrary, it is colder, so they sink to the bottom.

In agricultural aviation, jets $\mathrm{v}$ flow from the DP into an air stream, the velocity $V$ of which, for example, when using the $\mathrm{AN}-2$ aircraft, is equal to $37.8-44.4 \mathrm{~m} / \mathrm{s}$. Also, the angle $\beta$ between vectors and is not always straight.

The considered methods [5,7-9], as their analysis showed, do not take into account:

a) the value of the angle $\beta$ between the vectors $\vec{v}$ and $\vec{V}$, other than $90^{\circ}$;

b) the angle of inclination of this axis PT to the horizon;

c) the change along the DP of the velocities of the flow $\vec{V}$ and detachable jets $\vec{v}$;

d) change in the values of the coefficient $\mu_{(x)}$ of the liquid flow rate through the outlet;

e) change in the hydraulic coefficient of friction $\lambda_{(x)}$ along the DP;

f) kinematic and physical parameters of the flow outside the DP.

The reason for the neglect in the works [5,7-9] of the named parameters of the DP and the kinematic characteristics of the flow in it and the detached jets is the simplified solution of equations (1) and (2) [3], when these quantities are neglected. The neglect of these values was eliminated in [25]. The originality of the calculated equations (8) and (9) [25] lies in the fact that when solving the initial equation (2) [3], the variables along the distribution pipeline, the values of the hydraulic friction coefficient $\left(\lambda_{(x)} \neq\right.$ const $)$ and the coefficient of fluid flow through the outlet nozzles $\left(\mu_{(x)} \neq\right.$ const). Thus, the accuracy of the hydraulic calculation of pressure head DP has increased. Water consumption at the beginning of DP, calculated by formulas (8) and (9) [25], exceeds the experimental value by $6.25 \%$, and the flow rate obtained from expressions (5) and (6) [8] is $18.75 \%$ less from the experimental value (Fig. 13, $b$ ). The advantage of the technique [25] over the techniques [5, 7-9] is that equations (8) and (9) take into account the kinematic and physical parameters of the external fluid flow that washes the distribution pipeline. 
In the practical application of equations (8) and (9) [25], it should be taken into account that they give a practical coincidence of the calculated results with the experimental data only at $\beta=90^{\circ}$. So, the urgent task of hydromechanics is the creation of a mathematical model of fluid pressure flows with variable path flow rate, which provides accurate hydraulic calculation of distribution pipelines and collecting pipelines at angles of $0^{\circ} \leq \beta \leq 360^{\circ}$. The creation of such a model in the future will provide predictable regulation of the distribution pipeline operation, in particular, a controlled decrease in the unevenness of the path distribution of the liquid. Further development of research consists in improving equations (8), (9) [25] with respect to taking into account any values of the angles $\beta$ other than straight lines. To achieve this goal, the values of the flow coefficient $\mu(x)$ of the outlet cylindrical nozzles installed on the DP are experimentally established at different values of the jet detachment angle $\beta\left(0^{\circ} \leq \beta \leq 360^{\circ}\right)$ and at different values of the Reynolds criterion [28].

The authors of [31] continue to work on the creation of a reliable method for calculating pressure head DP. Simultaneously with the study of DP, work is being carried out to improve the design of pressure collecting pipelines [32, 33]. The latter require an approach similar to that used for calculating pressure distribution pipelines [29,33], which is reflected in the works $[1,30]$.

\section{Conclusions}

1. Studies carried out on an experimental distribution pipeline with gravitational water supply made it possible to determine the accuracy of calculations of the distribution of water along the pressure head DP, obtained by comparative methods. The inner diameter of the distribution pipe is $8.21 \mathrm{~mm}$, which is close to the DP used in practice. The experimental DP is equipped with eleven outlet nozzles with jets detaching from it at right angles. The value of the Reynolds criterion for the flow at the beginning of the DP was equal to 24568. Experimental DP is geometrically and hydrodynamically similar to DP, which are common in technological processes of various industries, for example, in pressure irrigation systems.

2. The water flow rate calculated by the method [25] is $6.25 \%$ higher than the experimental value, and the flow rate obtained by [8] is $18.75 \%$ lower than the experimental value. The method [25] for calculating pressure distribution pipelines provides more accurate calculation results in comparison with the method [8]. The increased accuracy of calculations by the method [25] is achieved by taking into account the variable values along the DP of the hydraulic friction coefficient $\lambda_{(x)}$ and the coefficient $\mu_{(x)}$ of the fluid flow rate through the original nozzles. The question of taking into account the angle $\beta_{(x)}$ between the vectors of the average velocity of the main fluid flow in the DP and the detachable jet $\vec{v}$, provided that it varies within $0^{\circ} \leq \beta_{(x)}=\leq 360^{\circ}$ remains unresolved.

\section{References}

1. Yakhno, O. M., Cherniuk, V. V., Hnativ, R. M. (2016). Napirni potoky zi zminnymy kharakterystykamy. Lviv: Vydavnytstvo Lvivskoi politekhniky, 408.

2. Bosak, N., Cherniuk, V., Matlai, I., Bihun, I. (2019). Studying the mutual interaction of hydraulic characteristics of waterdistributing pipelines and their spraying devices in the coolers at energy units. Eastern-European Journal of Enterprise Technologies, 3 (8 (99)), 23-29. doi: https://doi.org/10.15587/1729-4061.2019.166309

3. Petrov, G. A. (1964). Gidravlika peremennoy massy (Dvizhenie zhidkosti s izmeneniem raskhoda vdol' puti). Kharkiv: Har'kovskiy gosudarstvenniy universitet, 224.

4. Liu, H., Zong, Q., Lv, H., Jin, J. (2017). Analytical equation for outflow along the flow in a perforated fluid distribution pipe. PLOS ONE, 12 (10), e0185842. doi: https://doi.org/10.1371/journal.pone.0185842

5. Smyslov, V. V., Konstantinov, Yu. M. (1971). K raschyotu dyrchatyh trub s razdachey raskhoda vdol' puti. Gidravlika i gidrotekhnika, $12,47-52$.

6. Naumenko, I. I. (1980). Gidravlicheskiy raschet polivnyh truboprovodov kapel'nogo orosheniya. Gidravlika i gidrotekhnika, 30, 70-77.

7. Kovalenko, V. N., Boyko, V. I. (1989). Ob uravnenii ustanovivshegosya napornogo dvizheniya zhidkosti v tsilindricheskoy trube s otdeleniem raskhoda vdol' puti. Izvestiya vuzov. Stroitel'stvo i arhitektura, 4, 84-87.

8. Kravchuk, A. M., Kravchuk, O. Ya. (2015). Do metodyky hidravlichnoho rozrakhunku napirnykh perforovanykh rozpodilchykh truboprovodiv system vodopostachannia ta vodovidvedennia. Problemy vodopostachannia, vodovidvedennia ta hidravliky, 25, 117-124. Available at: http://nbuv.gov.ua/UJRN/PVVG_2015_25_20

9. Claudio, D. (1962). I condotti emungenti da in serbatoio. Contronto fra risultati teorici esperimentali atti e men. Accad. patav. scilettere ed arti, 74 (2), 188-197.

10. Berlamont, J., Van der Beken, A. (1973). Solutions for Lateral Outflow in Perforated Conduits. Journal of the Hydraulics Division, 99 (9), 1531-1549. doi: https://doi.org/10.1061/jyceaj.0003744

11. Povkh, I. L., Chernyuk, V. V. (1989). Resistance of converging sections during the turbulent flow of water with polyacrylamide additives. Journal of Engineering Physics, 57 (5), 1267-1270. doi: https://doi.org/10.1007/bf00871258

12. Chen, A., Sparrow, E. M. (2009). Turbulence modeling for flow in a distribution manifold. International Journal of Heat and Mass Transfer, 52 (5-6), 1573-1581. doi: https://doi.org/10.1016/j.ijheatmasstransfer.2008.08.006

13. Chen, A. W., Sparrow, E. M. (2009). Effect of exit-port geometry on the performance of a flow distribution manifold. Applied Thermal Engineering, 29 (13), 2689-2692. doi: https://doi.org/10.1016/j.applthermaleng.2008.12.035

14. Hassan, J. M., Mohamed, T. A., Mohammed, W. S., Alawee, W. H. (2014). Modeling the Uniformity of Manifold with Various Configurations. Journal of Fluids, 2014, 1-8. doi: https://doi.org/10.1155/2014/325259 
15. Zemlyanaya, N. V., Gulyakin, A. V. (2017). Analysis of Causes of Non-Uniform Flow Distribution in Manifold Systems with Variable Flow Rate along Length. IOP Conference Series: Materials Science and Engineering, 262, 012098. doi: https://doi.org/ $10.1088 / 1757-899 x / 262 / 1 / 012098$

16. Lee, S., Moon, N., Lee, J. (2012). A study on the exit flow characteristics determined by the orifice configuration of multi-perforated tubes. Journal of Mechanical Science and Technology, 26 (9), 2751-2758. doi: https://doi.org/10.1007/s12206-012-0721-z

17. Abubakar, S. S. (1977). Factors Affecting orifice Discharge in a Multi-outlet irrigation pipe. Manhattan, Kansas, 84. Available at: https://krex.k-state.edu/dspace/bitstream/handle/2097/26998/LD2668T41979A28.pdf?sequence=1\&isAllowed=y

18. Cherniuk, V. V., Ivaniv, V. V. (2016). Pat. No. 115840 UA. Sposib rehuliuvannia shliakhovoi vytraty ridyny v truboprovodakh z nasadkamy. No. a201611498; declareted: 14.11.2016; published: 26.12.2017, Bul. No. 24. Available at: https://uapatents.com/6115840-sposib-regulyuvannya-shlyakhovo-vitrati-ridini-v-truboprovodakh-z-nasadkami.html

19. Wang, C.-C., Yang, K.-S., Tsai, J.-S., Chen, I. Y. (2011). Characteristics of flow distribution in compact parallel flow heat exchangers, part II: Modified inlet header. Applied Thermal Engineering, 31 (16), 3235-3242. doi: https://doi.org/10.1016/ j.applthermaleng.2011.06.003

20. Kim, N.-H., Byun, H.-W. (2013). Effect of inlet configuration on upward branching of two-phase refrigerant in a parallel flow heat exchanger. International Journal of Refrigeration, 36 (3), 1062-1077. doi: https://doi.org/10.1016/j.ijrefrig.2012.12.001

21. Zeng, D., Pan, M., Tang, Y. (2012). Qualitative investigation on effects of manifold shape on methanol steam reforming for hydrogen production. Renewable Energy, 39 (1), 313-322. doi: https://doi.org/10.1016/j.renene.2011.08.027

22. Wang, P., Pan, W., Dai, G. (2020). A CFD-based design scheme for the perforated distributor with the control of radial flow. AIChE Journal, 66 (5). doi: https://doi.org/10.1002/aic.16901

23. García-Guendulain, J. M., Riesco-Ávila, J. M., Picón-Núñez, M. (2020). Reducing thermal imbalances and flow nonuniformity in solar collectors through the selection of free flow area ratio. Energy, 194, 116897. doi: https://doi.org/10.1016/j.energy.2020.116897

24. Singh, R. K., Rao, A. R. (2011). Fluid flow behavior and distribution in perforated tubes. Transactions, SMiRT, 21, 6-11. Available at: https://repository.lib.ncsu.edu/bitstream/handle/1840.20/32672/p365.pdf?sequence=1

25. Chernuk, V. V. (2008). Method of calculation of head power distributed conduit pipes. Applied hydromechanics, 10 (82 (3)), $65-76$. Available at: http://hydromech.org.ua/content/en/ph/10_3_65-76.html

26. Stepanov, M. P., Ovcharenko, I. H., Skobel'tsyn, Yu. A. (1984). Spravochnik po gidravlike dlya melioratorov. Moscow: Kolos, 207.

27. Chernyuk, V. V., Orel, V. I. (2009). Experimental Verification of a New Method of Calculation for Pressure Distributive Pipelines. Zeszyt Naukowy Politechniki Rzeszowskiej. Budownictwo i Inżynieria Środowiska, 266 (54), 27-34. Available at: https:// www.researchgate.net/publication/321052315_Experimental_Verification_of_a_New_Method_of_Calculation_for_Pressure_ Distributive_Pipelines

28. Cherniuk, V. V., Ivaniv, V. V., Bihun, I. V., Wojtowicz, J. M. (2019). Coefficient of Flow Rate of Inlet Cylindrical Nozzles with Lateral Orthogonal Inflow. Lecture Notes in Civil Engineering, 50-57. doi: https://doi.org/10.1007/978-3-030-27011-7_7

29. Ivaniv, V., Cherniuk, V., Kochkodan, V. (2020). Non-uniformity of Water Inflow into Pressure Collector-Pipeline Depending on the Values of Reynolds Criterion and of Inflow Jets Angles. Proceedings of EcoComfort 2020, 142-149. doi: https://doi.org/ 10.1007/978-3-030-57340-9_18

30. Kravchuk, A. M. Chernyshev, D. O., Kravchuk, O. A. (2021). Hidravlika napirnykh perforovanykh truboprovodiv ochysnykh sporud system vodopostachannia ta vodovidvedennia. Kyiv: Kyivskyi natsionalnyi universytet budivnytstva y arkhitektury, 207.

31. Kravchuk, A., Kochetov, G., Kravchuk, O. (2020). Improving the calculation of collecting perforated pipelines for water treatment structures. Eastern-European Journal of Enterprise Technologies, 6 (10 (108)), 23-28. doi: https://doi.org/10.15587/17294061.2020.216366

32. Polyakov, V., Kravchuk, A., Kochetov, G., Kravchuk, O. (2019). Clarification of aqueous suspensions with a high content of suspended solids in rapid sand filters. EUREKA: Physics and Engineering, 1, 28-45. doi: https://doi.org/10.21303/2461-4262.2019.00827

33. Cherniuk, V., Ivaniv, V. (2017). Influence of Values of Angle of Jet-joining on Non-uniformity of Water Inflow Along the Path in Pressure Collector-Pipeline. Proccedings of 10th International Conference «Environmental Engineering». doi: https://doi.org/ 10.3846/enviro.2017.073 